\title{
Use of point-of-care ultrasound in long bone fractures: a systematic review and meta-analysis
}

\author{
Lucas B. Chartier, MDCM, $\mathrm{MPH}^{*}{ }^{\ddagger}$; Laura Bosco, BSc ${ }^{\S}$; Lauren Lapointe-Shaw, MDCM ${ }^{\dagger \ddagger}$; \\ Jordan Chenkin, MD, MEd ${ }^{\ddagger \mathbb{T}}$
}

\section{ABSTRACT}

Objectives: Long bone fractures (LBFs) are among the most frequent traumatic injuries seen in emergency departments. Reduction and immobilization is the most common form of treatment for displaced fractures. Point-of-care ultrasound (PoCUS) is a promising technique for diagnosing LBFs and assessing the success of reduction attempts. This article offers a comprehensive review of the use of PoCUS for the diagnosis and reduction of LBFs.

Data source: MEDLINE and EMBASE databases were searched through July 19, 2015.

Study selection: We included prospective studies that assessed test characteristics of PoCUS in 1) the diagnosis or 2) the reduction of LBFs. The methodological quality of the included studies was evaluated using the Quality Assessment of Diagnostic Accuracy Studies (QUADAS-2) tool.

Data extraction: Thirty studies met inclusion criteria ( $n=3,506$; overall fracture rate $48.0 \%$ ). Test characteristics of PoCUS for the diagnosis of LBFs were as follows: sensitivity $64.7 \%-100 \%$, specificity $79.2 \%-100 \%$, positive likelihood ratio (LR) 3.11-infinity, and negative LR zero- 0.45 . Sensitivity and specificity for the adequate reduction of LBFs with PoCUS were $94 \%-100 \%$ and $56 \%-100 \%$, respectively. PoCUS diagnosis of pediatric forearm fractures in 10 studies showed a pooled sensitivity of $93.1 \% \quad(95 \%$ confidence interval [Cl], 87.2\%-96.4\%) and specificity of $92.9 \%$ (95\% Cl, 86.6\%-96.4\%), and PoCUS diagnosis of adult ankle fractures in four studies showed a pooled sensitivity of $89.5 \%$ $(95 \% \mathrm{Cl}, 77.0 \%-95.6 \%)$ and specificity of $94.2 \%(95 \% \mathrm{Cl}$, 86.1\%-97.7\%).

Conclusion: PoCUS demonstrates good diagnostic accuracy in all LBFs studied, especially in pooled results of diagnosis of pediatric forearm and adult ankle fractures. PoCUS is an appropriate adjunct to plain radiographs for LBFs.

\section{RÉSUMÉ}

Objectifs: Les fractures des os longs (FOL) figurent parmi les blessures traumatiques les plus fréquentes au service des urgences, et les traitements les plus courants des fractures avec déplacement consistent en la réduction et l'immobilisation du membre touché. L'échographie au point de service (EPS) est une technique prometteuse dans le diagnostic des FOL et dans l'évaluation de la réussite des tentatives de réduction. Aussi les auteurs ont-ils procédé à un examen exhaustif de la documentation médicale sur I'utilisation de I'EPS dans le diagnostic et la réduction des FOL, et ils font état des résultats dans le présent article.

Source de données: Des recherches ont été effectuées dans les bases de données MEDLINE et EMBASE jusqu'au 19 juillet 2015 inclusivement.

Sélection des etudes: Ont été retenues des études prospectives visant à évaluer les caractéristiques de fonctionnement de I'EPS au regard 1) du diagnostic ou 2) de la réduction des FOL. La qualité méthodologique des études sélectionnées a été évaluée I'aide de I'outil Quality Assessment of Diagnostic Accuracy Studies (QUADAS-2).

Extraction des données: Trente études respectaient les critères de sélection ( $n=3506$; taux général de fracture : $48,0 \%)$. Les caractéristiques de fonctionnement de l'EPS au regard du diagnostic des FOL se sont établies comme suit : sensibilité : 64,7 \% - $100 \%$; spécificité : 79,2 \% - $100 \%$; rapport de vraisemblance (RV) positif : 3,11 - infini; RV négatif : $0-0,45$. La sensibilité et la spécificité au regard de la réduction satisfaisante des FOL réalisée à l'aide de I'EPS étaient de $94 \%-100 \%$ et de $56 \%-100 \%$, respectivement. La qualité diagnostique de I'EPS dans les cas de fracture de l'avant-bras chez les enfants, reposant sur 10 études, a atteint une sensibilité globale de 93,1\% (intervalle de confiance [IC] à $95 \%: 87,2 \%-96,4 \%$ ) et une spécificité globale de 92,9 \% (IC à $95 \%: 86,6 \%-96,4 \%$ ), et la qualité diagnostique de I'EPS dans les cas de fracture de la cheville chez les adultes, reposant sur 4 études, a atteint une sensibilité globale de $89,5 \%$ (IC à $95 \%: 77,0 \%-95,6 \%$ ) et une spécificité globale de $94,2 \%$ (IC à $95 \%: 86,1 \%-97,7 \%$ ).

Conclusion: L'EPS a atteint une bonne exactitude diagnostique dans tous les cas de FOL examinés dans l'étude, tout particulièrement en ce qui concerne les résultats d'ensemble au regard du diagnostic des fractures de l'avant-bras chez les

From the ${ }^{*}$ Emergency Department and tDepartment of General Internal Medicine, University Health Network, Toronto, ON; $\neq$ Department of Medicine, University of Toronto, Toronto, ON; §School of Medicine, Queen's University, Kingston, ON; and the ПSunnybrook Health Sciences Centre, Emergency Medicine, Toronto, ON.

Correspondence to: Dr. Lucas B. Chartier, 200 Elizabeth St., RFE-GS-480, Toronto, ON M5G 2C4; Email: Lucas.Chartier@uhn.ca 
enfants et de celui des fractures de la cheville chez les adultes. L'EPS se révèle donc un examen complémentaire approprié des radiographies simples dans les cas de FOL.
Keywords: point-of-care systems, ultrasonography, fractures, bone, systematic review

\section{INTRODUCTION}

Fractures account for $17 \%$ of injuries in Canadians ages 12 and older. ${ }^{1}$ Long bone fractures (LBFs)-that is, fractures to the humerus, radius, ulna, femur, tibia or fibula-are most often caused by traumatic events such as motor vehicle accidents, sport injuries, falls, and assaults. $^{2}$ Immobilization, with or without reduction, is the most common treatment strategy for fractures in the emergency department (ED). ${ }^{3}$ Immobilization can be used as a temporizing measure until surgery is undergone or as a definitive treatment. In the latter case, adequate alignment is essential to optimize future functioning.

The diagnosis of LBFs is traditionally accomplished through plain radiographs taken at perpendicular angles to each other. Because of the resources required for around-the-clock radiographic capability, X-ray can be inaccessible in rural or remote areas, or in larger centres during off-hours. ${ }^{4}$ In settings where a radiography technologist is not present on-site, a point-of-care ultrasound (PoCUS) examination can be performed earlier, and at the bedside, reducing diagnostic delays and time to initiation of management. ${ }^{5}$ Additional advantages of PoCUS include its simplicity, portability, repeatability, and its lack of ionizing radiation.

Fluoroscopy has been advocated as an adjunct to ED-based fracture reduction. However, this technique can be impractical because of cost, size of the equipment, the training necessary for the use of this technology, the need for lead protectors on health care providers, as well as the harmful effects to patients of ionizing radiation. ${ }^{6}$

The benefits of PoCUS may be even greater for the reduction of displaced fractures, where localized swelling and significant pain may lead to inadequate reduction and repeated attempts, which are known to increase the likelihood of developing compartment syndrome. ${ }^{7}$ Moreover, repeated attempts may also put the patient through the risky process of sedation and/or analgesia multiple times, and could possibly lead to increased rates of operative management. ${ }^{8}$ PoCUS allows for real-time assessment of reduction attempts, making it possible to re-manipulate and immobilize the fracture while the patient is still sedated. PoCUS-guided fracture reduction and immobilization produces minimal discomfort when liberal amounts of transmission gel are used.

There are multiple studies and reports on the use of PoCUS in the setting of LBFs, but to our knowledge this is the first comprehensive review that includes a description of the technique and its application to LBF reduction. The objective of this study is to summarize and, where applicable, pool the diagnostic accuracy of PoCUS compared to plain radiographs in children and adults for 1) the diagnosis of suspected LBFs and 2) the adequate reduction of known LBFs.

\section{Description of the technique}

For the diagnosis of LBFs with PoCUS, the highfrequency linear probe should be used in the longitudinal plane, with a thick layer of ultrasound gel to minimize pain and improve visualization (Figure 1). The probe should be gently moved along the axis of the bone while adjusting the depth and gain to optimize the view. ${ }^{9,10}$ The deepest hyperechoic horizontal line on the PoCUS screen represents bony cortex, with its acoustic shadow preventing visualization of deeper structures. If a fracture is present, a discontinuity in this line will be seen (Figure 2, A). The degree of displacement and angulation of the distal fragment will

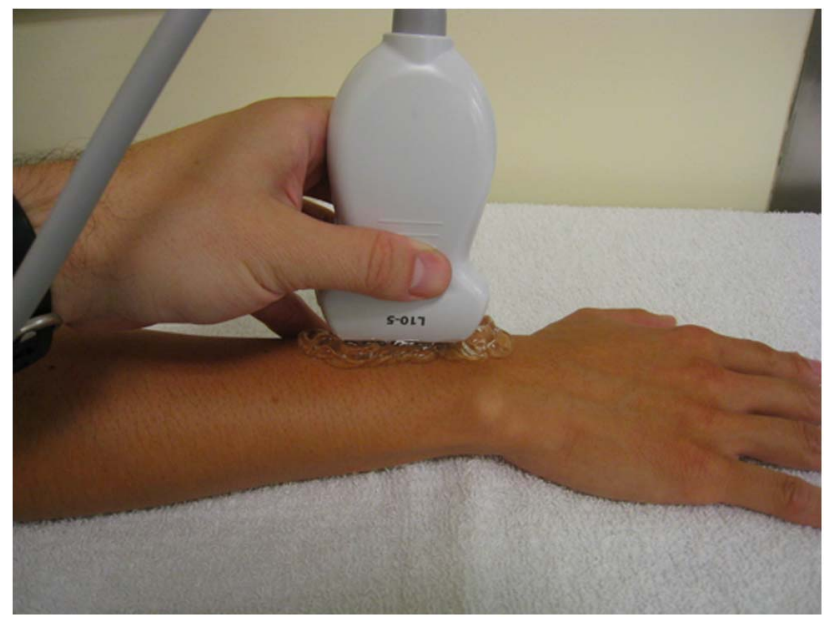

Figure 1. Simulated use of point-of-care ultrasound (PoCUS) for the diagnosis of distal radius fracture. 
(A)

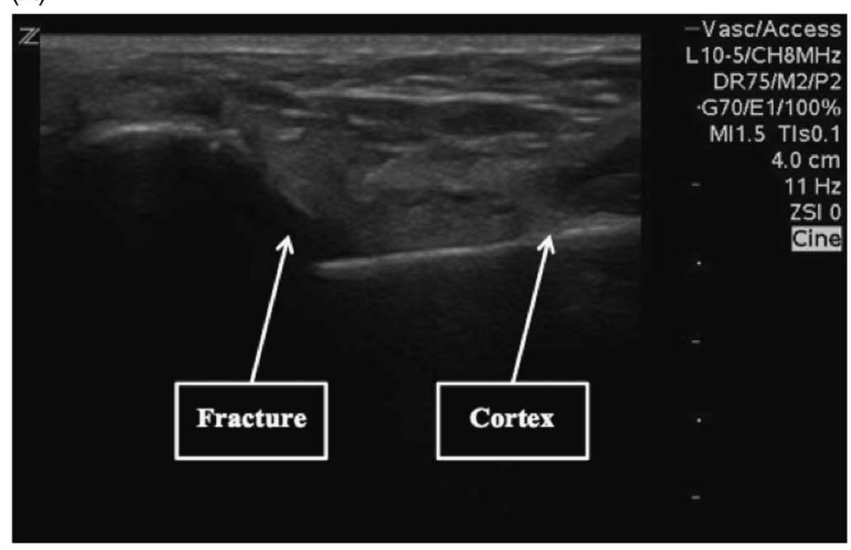

(B)

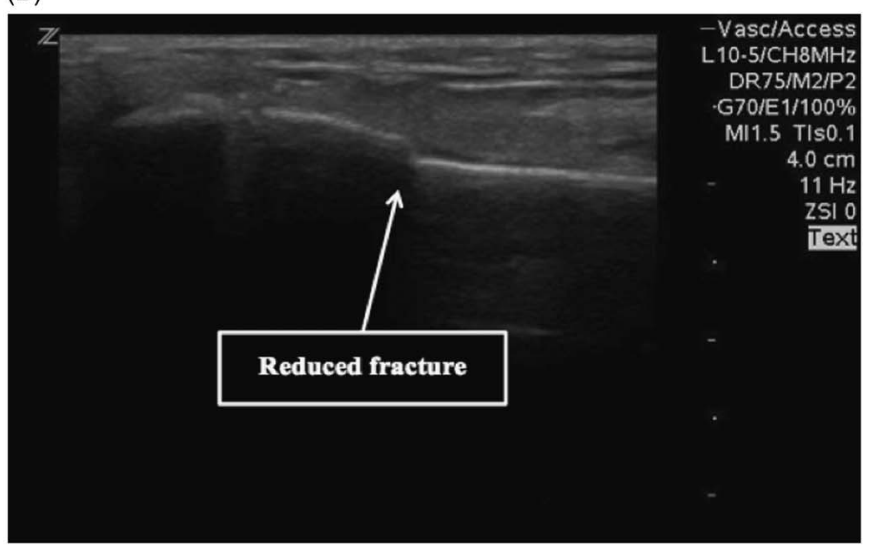

Figure 2. Diagnosis of $\mathrm{A}$ ) displaced distal radius fracture and $\mathrm{B}$ ) adequate reduction on the PoCUS screen. The patient's distal radius is to the left of the screen.

be visualized as a step-off and as an angulation between the cortices, respectively. ${ }^{9}$ Similar to plain radiography, the PoCUS examination should be obtained in two perpendicular planes for each bone of interest, ${ }^{11}$ as it minimizes the false-negative examinations from fractures that may be visualized at certain angles only. ${ }^{9}$

For PoCUS-guided reduction of LBFs, the fracture should be visualized with PoCUS prior to a reduction attempt, to provide a comparison for the post-reduction PoCUS images (Figure 2, B). If the post-reduction images do not appear satisfactory on PoCUS, based on step-off or angulation, additional attempts at reduction may be initiated in the same procedural sedation and/or analgesia episode. ${ }^{11}$ When the best possible reduction is achieved, the health care provider may proceed with immobilization of the fracture and usual care strategies, including post-reduction plain radiography. All relevant PoCUSgenerated images should be saved and archived for clinical and quality assurance purposes.

\section{METHODS}

\section{Eligibility criteria}

We included studies that prospectively enrolled patients with either suspected or known acute LBFs. Studies had to use PoCUS as the intervention, and compare it to plain radiography, the pragmatic standard of care. Studies had to report on the performance of PoCUS, either as a diagnostic or a management tool. Case reports and narrative review articles were excluded because they do not report diagnostic test characteristics. Other exclusion criteria included non-acute fractures, non-human models, or comparison done only with modalities other than plain radiography.

\section{Information sources}

MEDLINE and EMBASE databases were searched, from their earliest publication date to July 19, 2015. The search strategy was developed in conjunction with a health sciences librarian, and the strategy for the MEDLINE search is described in Supplementary Material Appendix 1 (available online).

\section{Study selection}

Two authors (LBC and $\mathrm{LB}$ ) reviewed the title and abstract of the retrieved articles to determine potential eligibility for inclusion in the manuscript, and manually searched the reference list of review articles for additional relevant studies. They subsequently performed a full-text review to identify studies meeting inclusion and exclusion criteria. Disagreements were resolved by consensus.

\section{Data collection process}

A data extraction sheet (based on the Cochrane Consumers and Communication Review Group's data extraction template) ${ }^{12}$ was pilot-tested for the first five studies, and refined according to the typical presentation of results. Information extracted from each study included type of study, study location, patient population, type of fracture and prevalence, number and specialty of the providers performing and interpreting PoCUS examinations, training that the providers 
received, the actual application of PoCUS (for initial diagnosis, reduction assessment, or both), and the performance characteristics of PoCUS accuracy, including sensitivity, specificity, and positive and negative likelihood ratios (LRs).

\section{Risk of bias in individual studies}

Methodological bias and applicability of the included studies were assessed using the Quality Assessment of Diagnostic Accuracy Studies (QUADAS-2) guidelines. ${ }^{13}$ As outlined in the 2011 guidelines, the authors agreed upon signaling questions that were pertinent to the review, encompassing five domains: patient selection, index test, reference standard, risk of bias, and concerns about applicability. Two of the authors (LBC and LB) independently performed the assessments, discrepancies were reconciled through discussion, and a consensus was reached.

\section{Summary measures}

The primary outcomes were the test characteristics of PoCUS compared to plain radiography for 1) the diagnosis of LBFs and 2) the successful reduction of LBFs. These included sensitivity, specificity, and positive and negative LRs. We also abstracted and reported additional measures of success in studies pertaining to the reduction of known LBFs, such as rates of repeat reduction and surgical management.

\section{Meta-analysis}

Where multiple studies reported on diagnostic accuracy under similar clinical and methodological conditions, a meta-analysis was performed. Forest plots were used to present sensitivity and specificity results from each study. In order to provide a quantitative measure of statistical heterogeneity, we used the model of diagnostic odds ratio used by DerSimonian and Laird. ${ }^{14,15}$ We reported Cochran's Q and Higgins' $\mathrm{I}^{2}$.

Results were pooled using the bivariate random effects model proposed by Reitsma et al. for meta-analysis of data on diagnostic accuracy. ${ }^{16}$ Results include estimates of the overall sensitivity, specificity, and the hierarchical summary receiver operating characteristic (HSROC) curve. In addition, Markov chain Monte Carlo sampling was used to produce summary estimates of $\mathrm{LR}(+)$ and $\mathrm{LR}(-)$ and their $95 \%$ confidence intervals (CIs). ${ }^{17}$
All analyses were performed using the mada package version $0.5 .4^{18}$ for $\mathrm{R}$ statistical software. ${ }^{19}$

\section{RESULTS}

\section{Study selection}

The literature search yielded 1,034 articles, which were screened by title and abstract (Figure 3). Upon performing manual searches of the bibliographies of the most recent review articles (less than 5 years from publication), 16 additional studies were retrieved. Based on the screening of these 1,050 articles by title and abstract, 948 studies were excluded. Upon a full-text review of the remaining 102 studies, 72 articles were excluded; reasons for exclusion are listed in Figure 3. Thirty studies were selected for inclusion in the systematic review: 23 for the diagnosis of LBFs, 5 for the management of LBFs, and 2 for the assessment of both outcomes. There were no disagreements between the authors.

\section{Study characteristics}

The 30 included studies recruited patients in unscheduled care environments, whether in the emergency or radiology departments, and almost all were in university-affiliated hospitals (Table 1). ${ }^{7,8,20-47}$ Two studies used a second reference standard for some of the patients, either computed tomography when the plain radiographs were not definitive or a daily clinical evaluation for 72 hours with delayed imaging or return to full duty for military personnel. ${ }^{34,42}$

Both the medical background and PoCUS training of the operators varied greatly across studies. Sixteen studies $(53.3 \%)$ had emergency physicians performing and interpreting PoCUS examinations, four studies (13.3\%) had surgeons (pediatric, hand, and/or orthopedic), five studies (16.7\%) had radiologists or ultrasound fellows or technicians, and four studies $(13.3 \%)$ included medical students or residents. The musculoskeletal PoCUS training received by the various operators ranged from a 3-minute tutorial followed by hands-on training, ${ }^{40}$ to a 1-month musculoskeletal ultrasound course. $^{33}$ On average, most providers received between 1 and 4 hours of didactic and practical training on basic PoCUS skills, which often focused on musculoskeletal indications. 


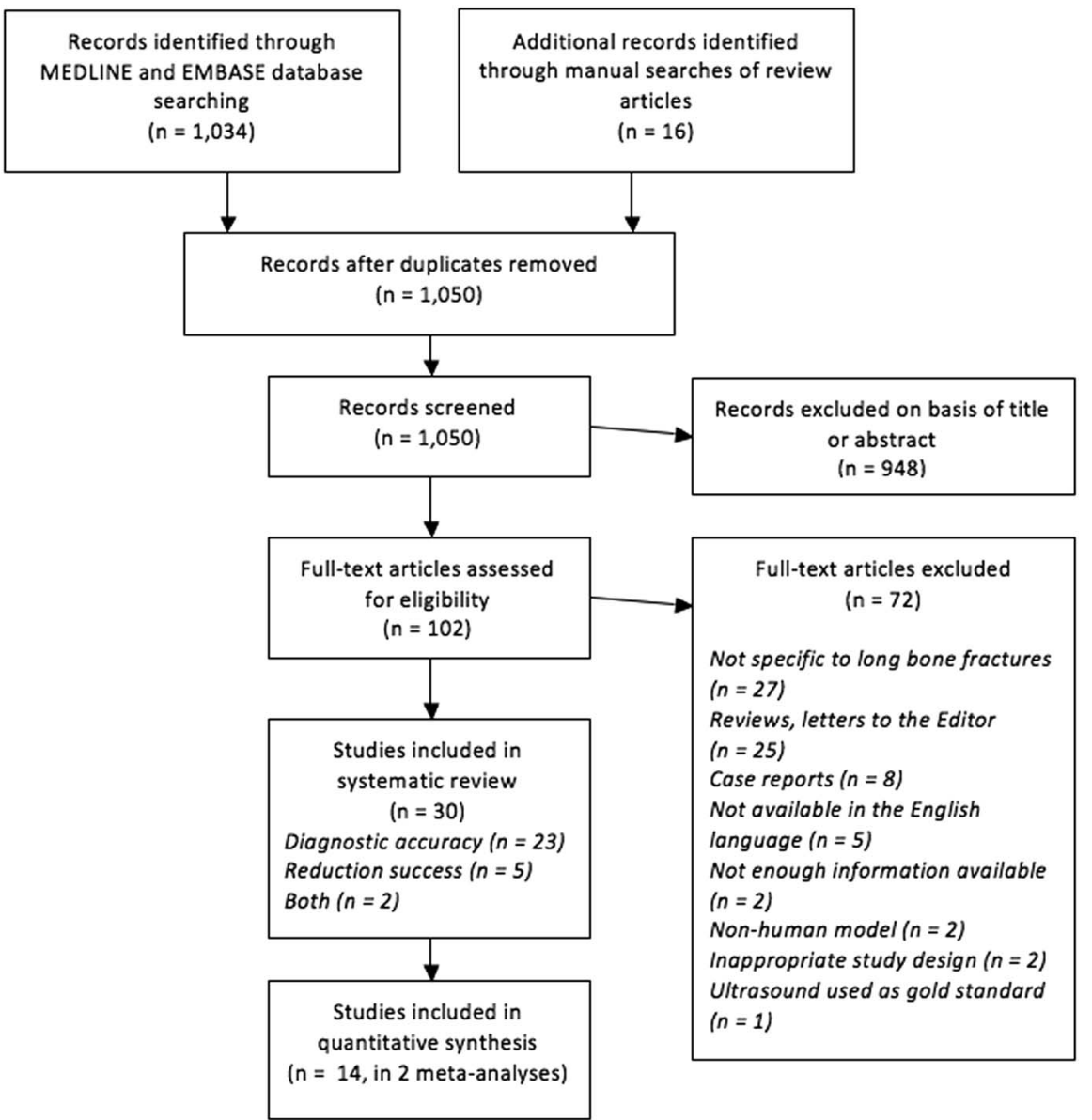

Figure 3. PRISMA flow diagram, including reasons for exclusions of the full-text articles reviewed.

\section{Diagnostic accuracy of PoCUS}

Table 2 shows the results of the systematic review for the studies pertaining to the diagnosis of LBFs with PoCUS. All studies reported both the sensitivity and specificity of PoCUS, and LRs were calculated from these values when the authors did not include them in their manuscripts. Twenty-five studies ${ }^{7,20-39,41-44}$ were included, ranging from 26 to 653 patients. Collectively, these studies included 2,982 patients and identified 1,200 fractures, with fracture prevalence ranging from $7 \%$ to $71 \%$ (aggregate prevalence of $40.2 \%$ ). Twelve of the $25(48 \%)$ studies focused on one body area only, either the forearm ${ }^{7,20-26}$ or the ankle, ${ }^{27-30}$ and 13 of $25(52 \%)$ studies recruited exclusively pediatric patients. ${ }^{7,20-26,31,36-39}$

Sensitivity for the detection of LBFs with PoCUS ranged from $64.7 \%$ to $100 \%$, with 20 of $25(80 \%)$ studies achieving rates of $>90 \%$. Specificity ranged from $79.2 \%$ to $100 \%$, with 21 of 25 (84\%) studies achieving rates of $>90 \%$. PoCUS was found to have an $\mathrm{LR}(+)$ ranging from 3.11 to infinity, with 19 of 25 $(76 \%)$ studies having an $\operatorname{LR}(+)$ above 10 . PoCUS was found to have an $\operatorname{LR}(-)$ ranging from zero to 0.45 , with 19 of $25(76 \%)$ studies having an $\operatorname{LR}(-)$ at or below 0.1 .

\section{Reduction success with PoCUS}

Table 3 shows the results of the systematic review for the studies pertaining to the management of LBFs with PoCUS. Seven studies were included, ${ }^{7,8,31,40,45-47}$ ranging from 27 to 164 patients. Collectively, these studies recruited 524 patients with 484 known fractures. Three studies recruited exclusively pediatric patients. ${ }^{7,31,45}$ Only one study did not specifically target patients with forearm fractures, ${ }^{31}$ and four focused specifically on distal radius fractures only. ${ }^{8,40,46,47}$ Despite these clinical similarities, there was significant methodological heterogeneity between included studies, thus precluding performance of a meta-analysis. 


\begin{tabular}{|c|c|c|c|c|c|}
\hline Author & Country & Study setting & \# of operators & Operator types & Operators training \\
\hline Herren, 2015 & Germany & $\mathrm{UAH}$ & Multiple & $\begin{array}{l}\text { Traumatology residents ( } 2 \text { nd- } \\
\text { 6th years of training) }\end{array}$ & $\begin{array}{l}30 \text { min training session for PoCUS use in detecting distal } \\
\text { forearm fractures; reference manual available }\end{array}$ \\
\hline Kozaci, 2015 & Turkey & UAH ED & Multiple & EPs & $\begin{array}{l}30 \mathrm{~min} \text { didactic and } 30 \mathrm{~min} \text { practical session on assessment } \\
\text { of distal radial fractures }\end{array}$ \\
\hline $\begin{array}{l}\text { Dallaudière, } 2015 \\
\text { Atilla, } 2014\end{array}$ & $\begin{array}{l}\text { France } \\
\text { Turkey }\end{array}$ & $\begin{array}{l}\text { UAH Radiology Dept } \\
\text { UAH ED }\end{array}$ & $\begin{array}{l}2 \\
5\end{array}$ & $\begin{array}{l}\text { Musculoskeletal radiologists } \\
\text { Sonographers }\end{array}$ & $\begin{array}{l}\text { NR } \\
\text { 4-hour theoretical and practical training by another EP } \\
\text { experienced in musculoskeletal PoCUS }\end{array}$ \\
\hline Kodama, 2014 & Japan & $\begin{array}{l}\text { UAH Out-patient } \\
\text { clinic/ED }\end{array}$ & 2 & Hand and orthopedic surgeons & $\begin{array}{l}\text { Trained with at least } 10 \text { cases of closed reduction with } \\
\text { PoCUS }\end{array}$ \\
\hline Boland-parvaz, 2013 & Iran & UAH ED & 1 & EP & 1-month musculoskeletal ultrasound course \\
\hline Waterbrook, 2013 & United States & UAH ED & 9 & $\begin{array}{l}2 \text { EPs, } 3 \text { sports medicine } \\
\text { fellows, } 3 \text { residents, one 4th- } \\
\text { year medical student }\end{array}$ & $\begin{array}{l}15 \text { min in-service from principal investigator on top of prior } \\
\text { training (none for EPs, usual residency training for } \\
\text { residents) }\end{array}$ \\
\hline Hedelin, 2013 & Sweden & UAH Orthopedic ED & 7 & Orthopedic surgeons & 30 min training by senior radiologist in basic PoCUS skills \\
\hline Ekinci, 2013 & Turkey & UAH ED & 1 & EP & $\begin{array}{l}\text { Informal training from musculoskeletal PoCUS workshops } \\
\text { and congresses }\end{array}$ \\
\hline Eckert, 2012a & Germany & UAH PED & N/A & N/A & N/A \\
\hline Eckert, 2012b & Germany & UAH PED & NR & & NR \\
\hline Barata, 2012 & United States & $\begin{array}{l}\text { UAH \& Suburban } \\
\text { Level-1 Trauma } \\
\text { Centre PED }\end{array}$ & 6 & $\begin{array}{l}2 \text { EPs, } 2 \text { ultrasound fellows, } \\
\text { two } 2 \text { nd-year EM residents }\end{array}$ & $\begin{array}{l}\text { 1-hour didactic and practical session from ED PoCUS } \\
\text { Director }\end{array}$ \\
\hline Beltrame, 2012 & Italy & UAH PED & 3 & Radiologists & NR \\
\hline Sinha, 2011 & India & $\begin{array}{l}\text { Urban Level-1 } \\
\text { Trauma Centre }\end{array}$ & 4 & EPs & $\begin{array}{l}\text { 1-day didactic program followed by a hands-on training } \\
\text { session to detect fractures }\end{array}$ \\
\hline Chaar-Alvarez, 2011 & United States & UAH PED & 4 & PEPs & Training through certified bedside emergency PoCUS course \\
\hline Canagasa-bey, 2011 & United Kingdom & UAH ED & NR & EPs & $\begin{array}{l}\text { 2-day course on musculoskeletal ultrasound that included } \\
\text { basic ankle assessment }\end{array}$ \\
\hline Chinnock, 2011 & United States & UAH ED & NR & EPs & $\begin{array}{l}\text { 3-min tutorial (or short computer tutorial) on PoCUS-guided } \\
\text { fracture reduction, followed by hands-on training }\end{array}$ \\
\hline Weinberg, 2010 & United States & UAH ED & 10 & PEPS & $\begin{array}{l}\text { 1-hour of musculoskeletal PoCUS training session (30 min } \\
\text { video, } 30 \mathrm{~min} \text { hands-on) }\end{array}$ \\
\hline Ang, 2010 & Singapore & $\begin{array}{l}\text { Community hospital } \\
\text { ED }\end{array}$ & Multiple & EPs & $\begin{array}{l}\text { Online lecture and instructional video followed by one-on-one } \\
\text { supervision by lead author (who gained prior experience } \\
\text { through pilot study of } 5 \text { patients) }\end{array}$ \\
\hline Ackermann, 2009 & Germany & UAH & N/A & N/A & N/A \\
\hline Patel, 2009 & United States & $\begin{array}{l}\text { Urban public } \\
\text { hospital PED }\end{array}$ & 3 & PEPS & $\begin{array}{l}\text { 2-hour didactic and practical session, then performed } 2 \\
\text { practice PoCUS examinations supervised by lead } \\
\text { investigator }\end{array}$ \\
\hline McNeil, 2009 & United States & Military hospital ED & Multiple & EPs & NR \\
\hline $\begin{array}{l}\text { Moritz, } 2008 \\
\text { Wong, } 2008\end{array}$ & $\begin{array}{l}\text { Germany } \\
\text { Singapore }\end{array}$ & $\begin{array}{l}\text { UAH } \\
\text { Referral hospital ED }\end{array}$ & $\begin{array}{c}\mathrm{N} / \mathrm{A} \\
3\end{array}$ & $\begin{array}{l}\text { N/A } \\
\text { EPs }\end{array}$ & $\begin{array}{l}\text { N/A } \\
\text { Prior completion of accredited training on basic PoCUS use } \\
\text { (i.e. FAST examination) }\end{array}$ \\
\hline Chen, 2007 & United States & UAH ED & 1 & PEPs & $\begin{array}{l}\text { Accredited PoCUS course, followed by } 1 \text { month of hands-on } \\
\text { training in ED }\end{array}$ \\
\hline Marshburn, 2004 & United States & $\begin{array}{l}3 \text { teaching hospital } \\
\text { EDs }\end{array}$ & 6 & $\begin{array}{l}3 \text { EPs, } 2 \text { EM residents, } 1 \\
\text { surgery resident }\end{array}$ & $\begin{array}{l}20 \text { min video, then } 40 \text { min practice session on live normal } \\
\text { model }\end{array}$ \\
\hline Chern, 2002 & Taiwan & UAH ED & 2 & Orthopedic surgeons & Prior experience with PoCUS \\
\hline Dulchavsky, 2002 & United States & $\begin{array}{l}\text { Urban trauma } \\
\text { hospital ED }\end{array}$ & Multiple & Cast technicians & 2-hour didactic and practical session \\
\hline Williamson, 2000 & United Kingdom & $\begin{array}{l}\text { Community hospital } \\
\text { Radiology Dept }\end{array}$ & 2 & Radiologists & NR \\
\hline Hübner, 2000 & Germany & UAH & 3 & Pediatric surgeons & $\begin{array}{l}\text { Performance of at least } 1,500 \text { scans and attendance at } \\
\text { training course on scanning bony surfaces }\end{array}$ \\
\hline
\end{tabular}




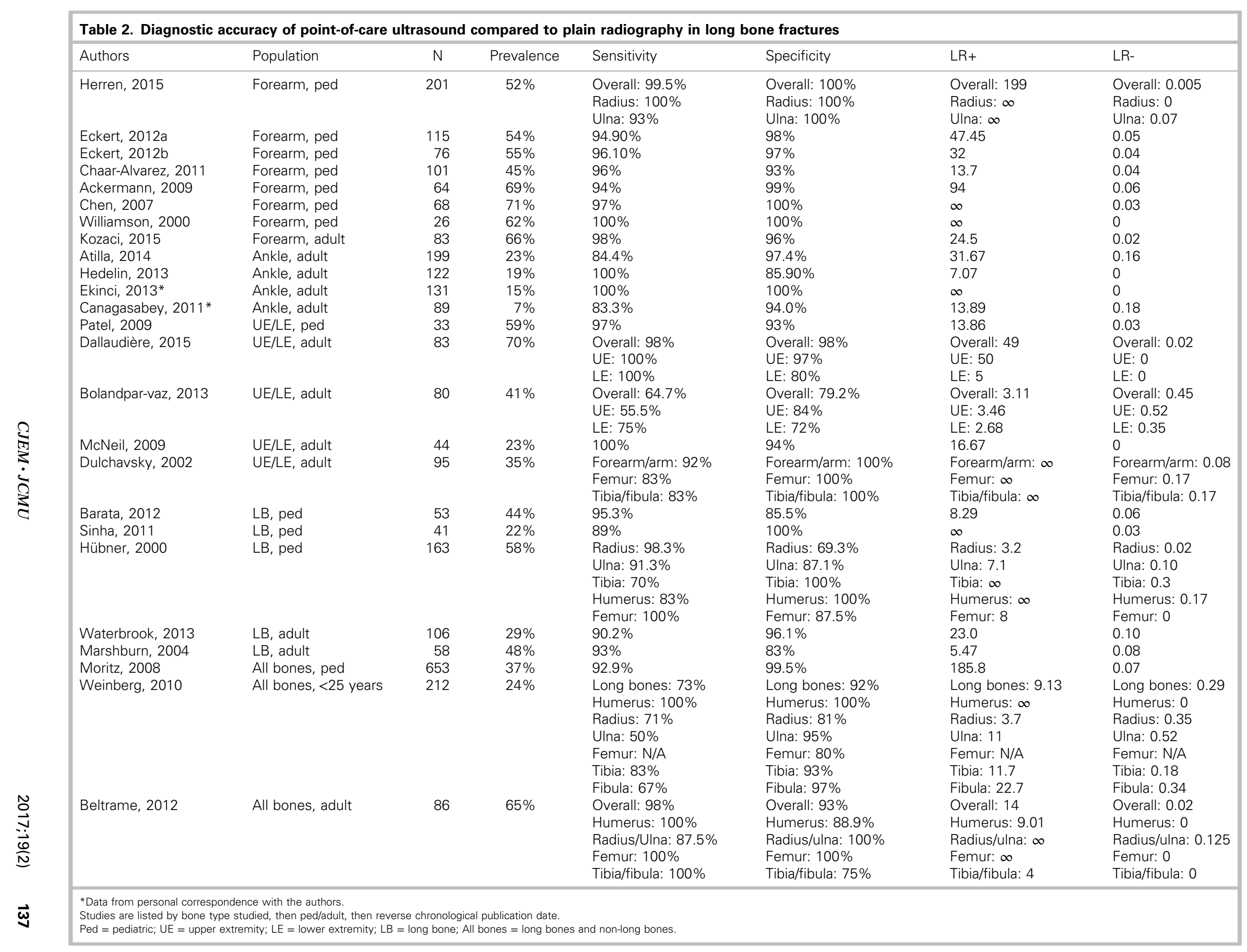




\begin{tabular}{|c|c|c|c|c|c|}
\hline Authors & Population & $\begin{array}{l}\text { Sample size } \\
\text { (n) }\end{array}$ & Prevalence & Sensitivity and specificity & Additional outcomes \\
\hline Wong, 2008 & Forearm, pediatric & 42 & $100 \%$ & NR & $\begin{array}{l}\text { Post-manipulation PoCUS corresponding with } \\
\text { Podipara }\end{array}$ \\
\hline Chen, 2007 & Forearm, pediatric & 68 & $71 \%$ & $\begin{array}{l}\text { Sensitivity: } 97 \%(95 \% \mathrm{Cl} \\
89 \%-100 \%) \\
\text { Specificity: } 100 \%(95 \% \mathrm{Cl} \text {, } \\
83 \%-100 \%)\end{array}$ & $\begin{array}{l}\text { Success rate of PoCUS-guided reduction: } \\
92 \%(95 \% \mathrm{Cl}, 75 \%-99 \%)\end{array}$ \\
\hline Patel, 2009 & $\begin{array}{l}\text { Upper/lower } \\
\text { extremity, } \\
\text { pediatric }\end{array}$ & 33 & $59 \%$ & $\begin{array}{l}\text { Sensitivity: } 100 \%(95 \% \mathrm{Cl} \\
60 \%-100 \%) \\
\text { Specificity: } 80 \%(95 \% \mathrm{Cl} \\
30 \%-99 \%)\end{array}$ & NR \\
\hline Kodama, 2014 & Forearm, adult & $\begin{array}{l}43 \text { (PoCUS) } \\
35 \text { (fluoroscopy) } \\
22 \text { (no imaging) }\end{array}$ & $100 \%$ & NR & $\begin{array}{l}\text { Success rate: PoCUS } 95 \% \\
\text { Success rate: fluoroscopy } 94 \% \\
\text { Success rate: no image } 68 \%\end{array}$ \\
\hline Chinnock, 2011 & Forearm, adult & 46 (PoCUS) & $100 \%$ & $\begin{array}{l}\text { Sensitivity: } 94 \%(95 \% \mathrm{Cl}, \\
\text { 88\%-98\%) } \\
\text { Specificity: } 56 \%(95 \% \mathrm{Cl} \\
31 \%-71 \%)\end{array}$ & NR \\
\hline Ang, 2010 & Forearm, adult & $\begin{array}{l}62 \text { (PoCUS) } \\
102 \text { (radiograph) }\end{array}$ & $100 \%$ & NR & $\begin{array}{l}\text { Rate of repeat reduction: } 1.6 \% \text { in PoCUS group } \\
\text { v. } 8.8 \% \text { in blind technique group ( } p=0.056) \\
\text { Operative rate: } 4.9 \% \text { for PoCUS group v. } 16.7 \% \\
\text { for blind technique group ( } p=0.02)\end{array}$ \\
\hline Chern, 2002 & Forearm, adult & 27 & $100 \%$ & NR & $\begin{array}{l}\text { Significant decrease in the displacement } \\
\text { distances and significant correction of the } \\
\text { fracture angle }(p<0.05) \text { with both PoCUS and } \\
\text { radiography } \\
\text { Significant association between the sonographic } \\
\text { and radiographic measurements at time of } \\
\text { injury and after closed reduction }\end{array}$ \\
\hline
\end{tabular}

The sensitivity and the specificity for the adequate reduction of LBFs with PoCUS ranged from 94\% to $100 \%$ and from $56 \%$ to $100 \%$, respectively. One study found a decrease in the rate of repeat manipulation and reductions, and showed better post-reduction volar tilt measurements and lower rates of operative management in patients with PoCUS-guided reduction compared to blind reduction. ${ }^{8}$ One other study found that PoCUS-guided reduction was successful in $95 \%$ of cases, as opposed to $68 \%$ with blind technique. ${ }^{46}$

\section{Meta-analysis of selected studies}

Only studies of two subpopulations of patients had sufficient clinical and methodological homogeneity to warrant performance of a meta-analysis: pediatric forearm and adult ankle fractures. Many studies that evaluated multiple bones amalgamated their results and had incomplete information on the relative prevalence of each type of fracture, thus preventing inclusion in the meta-analysis. We attempted to contact study lead authors but were successful for only two of these (Drs. Ekinci and Canagasabey; personal correspondence).

Ten studies were included in the meta-analysis of the PoCUS diagnosis of forearm fractures in pediatric patients. ${ }^{7,20-25,39,43,44}$ Forest plots of the included studies' sensitivity and specificity are shown in Figure 4. The studies' pooled test characteristics were as follows: sensitivity
93.1\% (95\% CI, 87.2\%-96.4\%), specificity 92.9\% (95\% CI, 86.6\%-96.4\%), LR(+) 14.1 (95\% CI, 6.71-25), and LR(-) 0.08 (95\% CI, 0.04-0.15). Supplementary Material Appendix 2 (available online) shows the HSROC curve, demonstrating very good test operating characteristics. The calculated Cochran's Q was 8.382 (9 df, $p=0.496$ ), and Higgins' $\mathrm{I}^{2}$ was $0 \%$, demonstrating statistical homogeneity between the included studies.

Four studies were included in the meta-analysis of the PoCUS diagnosis of ankle (distal tibia and fibula) fractures in adult patients. ${ }^{27-30}$ Because they are clinically different, we did not include studies of pediatric or mixed age patients, or studies of patients with mid-shaft lower leg fractures. ${ }^{35,39,43,44}$ Forest plots of the included studies' sensitivity and specificity are shown in Figure 5. The studies' pooled test characteristics were as follows: sensitivity $89.5 \%$ (95\% CI, 77.0\%-95.6\%), specificity 94.2\% (95\% CI, 86.1\%-97.7\%), LR(+) 16.4 (95\% CI, 6.57-33.5), and LR(-) 0.12 (95\% CI, 0.05-0.24). Supplementary Material Appendix 3 (available online) shows the HSROC curve, demonstrating good test characteristics. The calculated Cochran's Q was 3.834 ( $3 \mathrm{df}, p=0.28$ ), and Higgins' $\mathrm{I}^{2}$ was $21.75 \%$, demonstrating statistical homogeneity between the included studies.

\section{Risk of bias}

Supplementary Material Appendix 4 (available online) shows the assessment of methodological bias 

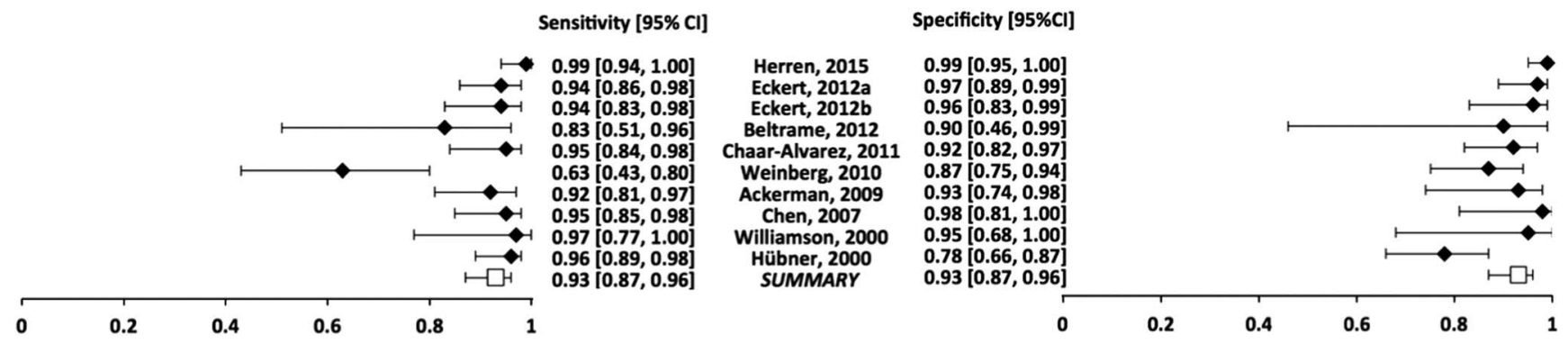

Figure 4. Forest plots of the sensitivity and specificity of studies included in the meta-analysis of pediatric forearm fractures. Point estimates are presented with their $95 \%$ confidence intervals.

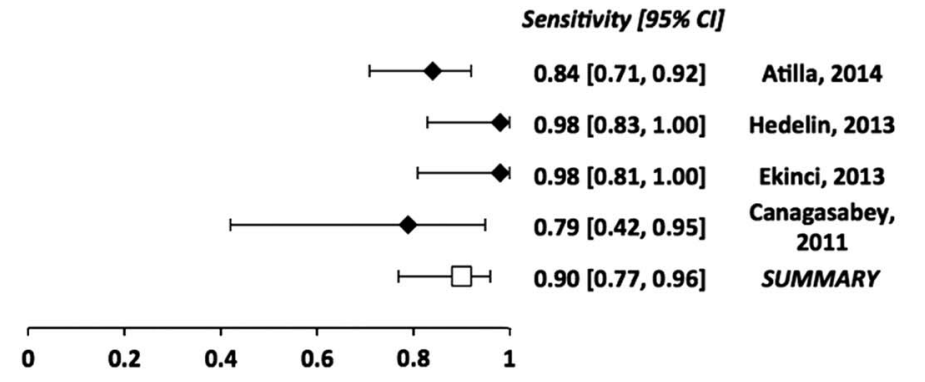

Specificity [95\% CI]

$0.97[0.93,0.99]$

$0.86[0.77,0.91]$

$1.00[0.96,1.00]$

$0.93[0.86,0.97]$

$0.94[0.86,0.98]$

\begin{tabular}{llllll}
\hline 0 & 0.2 & 0.4 & 0.6 & 0.8 & 1
\end{tabular}

Figure 5. Forest plots of the sensitivity and specificity of studies included in the meta-analysis of adult ankle fractures. Point estimates are presented with their $95 \%$ confidence intervals.

and applicability of the included studies, using the 2001 QUADAS-2 guidelines. All studies used convenience as opposed to consecutive sampling, mostly due to the small number of PoCUS-trained providers available. All PoCUS examinations pertaining to the diagnosis of LBFs occurred before radiographs were taken. Management of patients was always based on the results of the radiographs. Only 3 of 30 (10\%) studies reported on the inter-rater reliability of PoCUS: $78 \%$ agreement in one study, and kappa values of 0.57 and 0.92 in two others. ${ }^{23,40,41}$ Only one study explicitly reported on a quality assurance process, with one senior sonologist reviewing all enrolled patients' scans. ${ }^{43}$ Twenty-nine studies used plain radiographs as the only reference test for LBFs, with one using computed tomography as a secondary confirmatory tool only if necessary. ${ }^{42}$ Twenty-five studies reported on the presence of PoCUS training prior to initiating the study. Overall, all studies were of good methodological quality and were felt to be appropriate for inclusion in the analysis of this review.

\section{DISCUSSION}

Our review of the literature on the accuracy of PoCUS for the diagnosis of LBFs included 25 studies and 2,982 patients, of which 20 reported sensitivity rates of $>90 \%$, and 21 specificity rates of $>90 \%$. Pooled results of the meta-analyses demonstrated good performance characteristics, with a sensitivity of $93.1 \%$ and specificity of $92.9 \%$ for pediatric forearm fractures, and a sensitivity of $89.5 \%$ and specificity of $94.2 \%$ for adult ankle fractures. Seven studies of PoCUS for the reduction of LBFs met inclusion criteria, comprising 524 patients, and all demonstrated success rates of above $90 \%$. As practitioners become more proficient with PoCUS over time, its accuracy may improve further. However, although the current evidence is promising, large randomized controlled trials (RCTs) are needed to confirm the benefits seen in smaller, non-randomized trials.

PoCUS, a relatively new tool in the emergency physician's armamentarium, is a powerful and useful adjunct to the clinical assessment and plain radiographs. In some settings, PoCUS may be preferable to plain radiographs, because of its ease of use and portability. Nonetheless, the need for medicolegal documentation, as well as baseline images with which to compare follow-up radiographs, justify the continued use of traditional diagnostic imaging in settings where it is available. The studies that reported lower PoCUS accuracy tended to be those that recruited adult (versus pediatric) patients, and that assessed multiple bones 
(versus focusing on one specific body area only). This may indicate that the PoCUS examination is easier to accomplish and/or to interpret in pediatric patients, and that there is a learning curve associated with each specific bone being assessed.

In 2013, Joshi et al. published a review of the diagnostic accuracy of history, physical examination, and bedside ultrasound for the diagnosis of extremity fractures in the ED. ${ }^{48}$ In addition to eight articles that had not been published at that time, ${ }^{20,26-28,32,33,41,46}$ our study includes thirteen other articles not included in that review. ${ }^{21,22,24,25,29,30,34-36,38,41,43,44}$ Additional studies were possibly found as a result of a more comprehensive search strategy. Our review reaches similar conclusions, that PoCUS is a useful tool to supplement radiographs for the detection of fractures. We have provided an inclusive and updated review of the literature regarding the use of PoCUS in LBFs. Given the increasing proportion of emergency medicine practitioners who have access to and use PoCUS regularly, we hope that this article can serve as a reference to inform their practice with regards to LBFs.

As with any newer technology or procedure, training remains the most important challenge. Without proper training, practitioners run the risk of having a large number of false-positive or negative examinations, which may lead to worse patient outcomes. In the three studies where it was reported, the inter-reliability ranged from moderate to very good. However, training undergone by clinicians in these studies was minimal (3-minute tutorial, 15-minute bedside teaching, and knowledge from prior completion of a general bedside ultrasound course), and further training may therefore have increased their accuracy.

\section{LIMITATIONS}

Many of the included studies had small samples sizes, and none were RCTs. Overall, $40 \%$ of the recruited patients with possible LBF were diagnosed with a fracture with the reference test. This is likely higher than the true proportion of LBFs in undifferentiated patients presenting to most EDs with traumatic pain, swelling, or deformity. This may have been affected by the convenience sample selected by all authors, which introduces bias in the selected population. This recruitment strategy, by a small number of motivated PoCUS practitioners, may also have affected the results and limits the generalizability of our study findings. The lack of inter- and intra-rater reliability in most studies is also a limitation. However, the fact that in many studies the providers had no prior PoCUS experience and only limited training is reassuring for clinicians beginning to use musculoskeletal PoCUS.

\section{CONCLUSION}

This systematic review and meta-analysis summarizes current knowledge regarding the use of PoCUS in LBFs. The 30 prospective studies, including 2,982 individual patients, showed good test characteristics for the diagnosis and reduction of LBFs. Although results were varied, most studies reported sensitivities and specificities of $90 \%$ and above for the diagnosis of LBF with PoCUS, including in the two meta-analyses targeting pediatric forearm and adult ankle fractures. Although PoCUS should not completely replace the use of plain radiography at the current time, this review demonstrates that it is a powerful adjunct in all cases and could be used as a reasonable alternative in certain settings.

RCTs are needed to further the current knowledge on the use of PoCUS for the diagnosis and management of LBFs. Specifically, future studies should focus on determining standards for appropriate training and credentialing, on patient-centered outcomes such as satisfaction and morbidity, and on the cost-effectiveness of the use of PoCUS in the ED. In low-resource settings where access to plain radiographs may be challenging or minimal, studies should focus on the feasibility and safety of using PoCUS as an alternative to plain radiographs.

Acknowledgements: The authors wish to acknowledge the support of Henry Lam, librarian and information specialist, for his help defining the systematic review search strategy.

Competing interests: None declared.

\section{SUPPLEMENTARY MATERIALS}

To view supplementary material for this article, please visit https://doi.org/10.1017/cem.2016.397

\section{REFERENCES}

1. Billette JM, Janz T. Statistics Canada. Injuries in Canada: insights from the Canadian community health survey; 2011. Available at: http://www.statcan.gc.ca/pub/82-624-x/2011001/ article/11506-eng.htm\#a4 (accessed 23 July 2015). 
2. Cohen PH. BMJ Best Practice. Long bone fractures; 2015. Available at: http://bestpractice.bmj.com.proxy.queensu.ca/ best-practice/monograph/386/resources/credits.html (accessed 23 July 2015).

3. Geiderman JM, Katz D. General principles of orthopedic injuries. In Marx J, Hockberger R, Walls R (eds.). Rosen's emergency medicine - concepts and clinical practice, 8th ed. Amsterdam: Elsevier; 2013, 511-33.

4. Sippel S, Muruganandan K, Levine A, et al. Review article: use of ultrasound in the developing world. Int 7 Emerg Med 2011;4:72.

5. Grechenig W, Clement HG, Schatz B, et al. Value of ultrasound of the support and locomotor system - with special reference to radiation exposure and cost reduction. Biomed Tech 1997;42(5):132-7.

6. Brenner DJ, Doll R, Goodhead DT, et al. Cancer risks attributable to low doses of ionizing radiation: assessing what we really know. Proc Natl Acad Sci USA 2003; 100(24):13761-6.

7. Chen L, Kim Y, Moore CL. Diagnosis and guided reduction of forearm fractures in children using bedside ultrasound. Pediatr Emerg Care 2007;23(8):528-53.

8. Ang SH, Lee SW, Lam KY. Ultrasound-guided reduction of distal radius fracture. Am 7 Emerg Med 2010;28(9):1002-8.

9. Majeed M, Mukherjee MA, Paw R. Ultrasound-guided hematoma block and fracture reduction: a new way to go forward. Crit Care 2010;14(Suppl 1):P269.

10. Cross KP. Bedside ultrasound for pediatric long bone fractures. Clin Pediatr Emerg Med 2011;12(1):27-36.

11. Saul $\mathrm{T}, \mathrm{Ng} \mathrm{L}$, Lewiss RE. Point-of-care ultrasound in the diagnosis of upper extremity fracture-dislocation. A pictorial essay. Med Ultrason 2013;15(3):230-6.

12. Higgins JPT, Green S (eds.). Cochrane handbook for systematic reviews of interventions. West Sussex: John Wiley \& Sons; 2011.

13. Whiting PF, Rutjes AWS, Westwood ME, et al. QUADAS2: A Revised Tool for the Quality Assessment of Diagnostic Accuracy Studies. Ann Intern Med 2011;155(8):529-36.

14. DerSimonian R, Laird N. Meta-analysis in clinical trials. Control Clin Trials 1986;7(3):177-88.

15. Doebler P, Holling H. Meta-analysis of diagnostic accuracy with mada; 2015. Available at: https://cran.r-project.org/web/ packages/mada/vignettes/mada.pdf (accessed 3 January 2016).

16. Reitsma JB, Glas AS, Rutjes AW, et al. Bivariate analysis of sensitivity and specificity produces informative summary measures in diagnostic reviews. 7 Clin Epidemiol 2005; 58(10):982-90.

17. Zwinderman AH, Bossuyt PM. We should not pool diagnostic likelihood ratios in systematic reviews. Stat Med 2008;27(5):687-97.

18. Doebler P. Mada: meta-analysis of diagnostic accuracy; 2015. Available at: http://CRAN.R-project.org/package=mada (accessed 3 January 2016).

19. R Core Team. R: a language and environment for statistical computing Vienna, Austria; 2013. Available at: http://www. R-project.org/ (accessed 3 January 2016).

20. Herren C, Sobottke R, Ringe MJ, et al. Ultrasound-guided diagnosis of fractures of the distal forearm in children. Orthop Traumatol Surg Res 2015;101(4):501-5.
21. Eckert K, Ackermann O, Schweiger B, et al. Ultrasound as a viable alternative to standard $\mathrm{X}$-rays for the diagnosis of distal forearm fractures in children. Z Orthop Unfall 2012a; 150(4):409-14.

22. Eckert K, Ackermann O, Schweige B, et al. Sonographic diagnosis of metaphyseal forearm fractures in children. Pediatr Emerg Care 2012b;28(9):851-4.

23. Chaar-Alvarez FM, Warkentine F, Cross K, et al. Bedside ultrasound diagnosis of non-angulated distal forearm fractures in the pediatric emergency department. Pediatr Emerg Care 2011;27(11):1027-32.

24. Ackermann O, Liedgens P, Eckert K, et al. Ultrasound diagnosis of forearm fractures in children: a prospective multicenter study. Unfallchirurg 2009;112(8):706-11.

25. Williamson D, Watura R, Cobby M. Ultrasound imaging of forearm fractures in children: a viable alternative? $\mathcal{F}$ Accid Emerg Med 2000;17(1):22-4.

26. Kozaci N, Ay MO, Akcimen M, et al. Evaluation of the effectiveness of bedside point-of-care ultrasound in the diagnosis and management of distal radius fractures. $A m \mathcal{7}$ Emerg Med 2015;33(1):67-71.

27. Atilla OD, Yesilaras M, Kilic TY, et al. The accuracy of bedside ultrasonography as a diagnostic tool for fractures in the ankle and foot. Acad Emerg Med 2014;21(9):1058-61.

28. Hedelin H, Goksör LÅ, Karlsson J, et al. Ultrasound assisted triage of ankle trauma can decrease the need for radiographic imaging. Am 7 Emerg Med 2013;31(12):1686-9.

29. Ekinci S, Polat O, Günalp M, et al. The accuracy of ultrasound evaluation in foot and ankle trauma. Am 7 Emerg Med 2013;31(11):1551.

30. Canagasabey MD, Callaghan MJ, Carley S. The Sonographic Ottawa Foot and Ankle Rules study (the SOFAR study). Emerg Med 7 2011;28(10):838-40.

31. Patel DD, Blumberg SM, Crain EF. The utility of bedside ultrasonography in identifying fractures and guiding fracture reduction in children. Pediatr Emerg Care 2009;25(4):221-5.

32. Dallaudière B, Larbi A, Lefere $M$, et al. Musculoskeletal injuries in a resource-constrained environment: comparing diagnostic accuracy of on-the-spot ultrasonography and conventional radiography for bone fracture screening during the Paris-Dakar rally raid. Acta Radiol Open 2015;4(5):PMC4447636.

33. Bolandparvaz S, Moharamzadeh $\mathrm{P}$, Jamali $\mathrm{K}$, et al. Comparing diagnostic accuracy of bedside ultrasound and radiography for bone fracture screening in multiple trauma patients at the ED. Am 7 Emerg Med 2013; 31(11):1583-5.

34. McNeil CR, McManus J, Mehta S. The accuracy of portable ultrasonography to diagnose fractures in an austere environment. Prebosp Emerg Care 2009;13:50-2.

35. Dulchavsky SA, Henry SE, Moed BR, et al. Advanced ultrasonic diagnosis of extremity trauma: the FASTER examination. $\mathcal{F}$ Trauma 2002;53(1):28-32.

36. Barata I, Spencer R, Suppiah A, et al. Emergency ultrasound in the detection of pediatric long-bone fractures. Pediatr Emerg Care 2012;28:1154-7.

37. Sinha TP, Bhoi S, Kumar S, et al. Diagnostic accuracy of bedside emergency ultrasound screening for fractures in pediatric trauma patients. 7 Emerg Trauma Shock 2011; $4(4): 443-5$. 
38. Moritz JD, Berthold LD, Soenksen SF, et al. Ultrasound in diagnosis of fractures in children: unnecessary harassment or useful addition to X-ray? Ultraschall Med 2008;29(3):267-74.

39. Hübner U, Schlicht $W$, Outzen $S$, et al. Ultrasound in the diagnosis of fractures in children. 7 Bone foint Surg 2000;82-B:1170-3.

40. Chinnock B, Khaletskiy A, Kuo K, et al. Ultrasound-guided reduction of distal radius fractures. 7 Emerg Med 2011; 4(3):308-12.

41. Waterbrook AL, Adhikari S, Stolz U, et al. The accuracy of point-of-care ultrasound to diagnose long bone fractures in the ED. Am 7 Emerg Med 2013;31(9):1352-6.

42. Marshburn TH, Legome E, Sargsyan A, et al. Goal-directed ultrasound in the detection of long-bone fracture. 7 Trauma 2004;57:329-32.

43. Weinberg ER, Tunik MG, Tsung JW. Accuracy of clinicianperformed point-of-care ultrasound for the diagnosis of fractures in children and young adults. Injury 2010;41(8):862-8.
44. Beltrame V, Stramare R, Rebellato N, et al. Sonographic evaluation of bone fractures: a reliable alternative in clinical practice? Clin Imaging 2012;36:203-8.

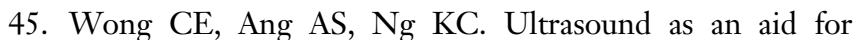
reduction of paediatric forearm fractures. Int 7 Emerg Med 2008;1(4):267-71.

46. Kodama N, Takemura $\mathrm{Y}$, Ueba $\mathrm{H}$, et al. Ultrasoundassisted closed reduction of distal radius fractures. 7 Hand Surg Am 2014;39(7):1287-94.

47. Chern T, Jou I, Lai K, et al. Sonography for monitoring closed reduction of displaced extraarticular distal radial fractures. 7 Bone foint Surg 2002; 84(2):194-203.

48. Joshi N, Lira A, Mehta N, et al. Diagnostic accuracy of history, physical examination, and bedside ultrasound for diagnosis of extremity fractures in the emergency department: a systematic review. Acad Emerg Med 2013; 20(1):1-15. 